\title{
Mode Evaluation and Structure Design of Connection between Pole and Base of Roadside Breakaway Sign in China
}

\author{
Liang Xu, ${ }^{1}$ Guozhu Cheng, ${ }^{2}$ Qiuyue Jiang, ${ }^{3}$ and Yufeng Guo ${ }^{1}$ \\ ${ }^{1}$ School of Civil Engineering, Changchun Institute of Technology, Changchun 130012, China \\ ${ }^{2}$ School of Transportation Science and Engineering, Harbin Institute of Technology, Harbin 150090, China \\ ${ }^{3}$ School of Mechatronics Engineering, Changchun Institute of Technology, Changchun 130012, China \\ Correspondence should be addressed to Guozhu Cheng; guozhucheng@126.com
}

Received 12 October 2015; Revised 30 November 2015; Accepted 10 December 2015

Academic Editor: Heiner Bubb

Copyright (c) 2016 Liang Xu et al. This is an open access article distributed under the Creative Commons Attribution License, which permits unrestricted use, distribution, and reproduction in any medium, provided the original work is properly cited.

\begin{abstract}
In order to present reliable mode and structure of connection between pole and base for breakaway sign, mode evaluation and structure design were conducted in this paper. AHP was adopted to evaluate connection modes between sign pole and base. Analytic hierarchy with double criterion layer and corresponding judgment matrix were established. Through qualitative analysis, powers of indexes were given and evaluation results were presented based on standardization process of each evaluation index. It shows that brittle connection mode comes in the first place, the plastic connection mode comes second, and rigid connection mode comes last. Two brittle connection structures were designed through the finite element simulation analysis. By ANSYS software, stress data were given for recessed and hole-type connection design structure. It can be found that maximum tensile stress data of two connection structures are all more than ultimate tensile strength of steel. Thus it can be concluded that two connection structures designed in this paper can be breakaway in collision and protect the safety of vehicle occupants.
\end{abstract}

\section{Introduction}

In the 1970s, American scholars put forward the "forgiving" concept in road design. It is inevitable to make mistakes when driving, and some traffic accidents that may result from those mistakes should not have brought passengers sure death in the vehicle. Roadside breakaway sign is an important part of forgiving design.

The theory of energy dissipation was first put forward by Texas Transportation Institute of the USA in The Braced Structure of Breakaway Roadside Signs in 1967 [1]. Ivey et al. conducted tests to determine the feasibility of large breakaway supports for the bridges in 1971 [2]. Martinez et al. presented the general design considerations and the results of the mathematical simulation of vehicle collision with overhead sign bridges mounted on breakaway supports in 1971 [3]. Kimball and Michie conducted ten pendulum impact tests of breakaway wood sign supports to evaluate safety performance in 1978 [4]. Szalaj and Hollinger conducted simulated and actual crash tests on a New Jersey breakaway sign structure in 1985 [5]. Anon concluded in 1988 that breakaway supports for signs should fail in a predictable manner when hit head-on by $1,800 \mathrm{lb}$. vehicle, or its equivalent, at speeds of 20 and $60 \mathrm{mph}$ [6]. Davis stated in 1990 that the 12 in. clearance from the bottom of the sign to the pavement and 0.024 in. thick aluminum signs with 29 and $41 \mathrm{in}$. of clearance passed the wind and crash tests and were recommended for implementation [7]. Reid proposed a modified dual-support breakaway sign system in 1996 [8]. Paulsen and Reid modeled a dual support breakaway sign system using LS-DYNA3D in 1996 [9]. Pinelli et al. presented the breakaway connection with spring washers in 2002 to ensure that the bolts are tensioned to the proper value [10]. In 2010, FHWA-SA-09-025 introduced design size of wood post, U-channel steel post, and I-Beam steel post with a breakaway feature [11]. In 2011, the American AASHTO published the 4th edition of Roadside Design Guide, which serves as an important guide specification for American roadside safety design [12]. In addition, the European traffic safety scholars also did some researches about the roadside traffic facilities. 


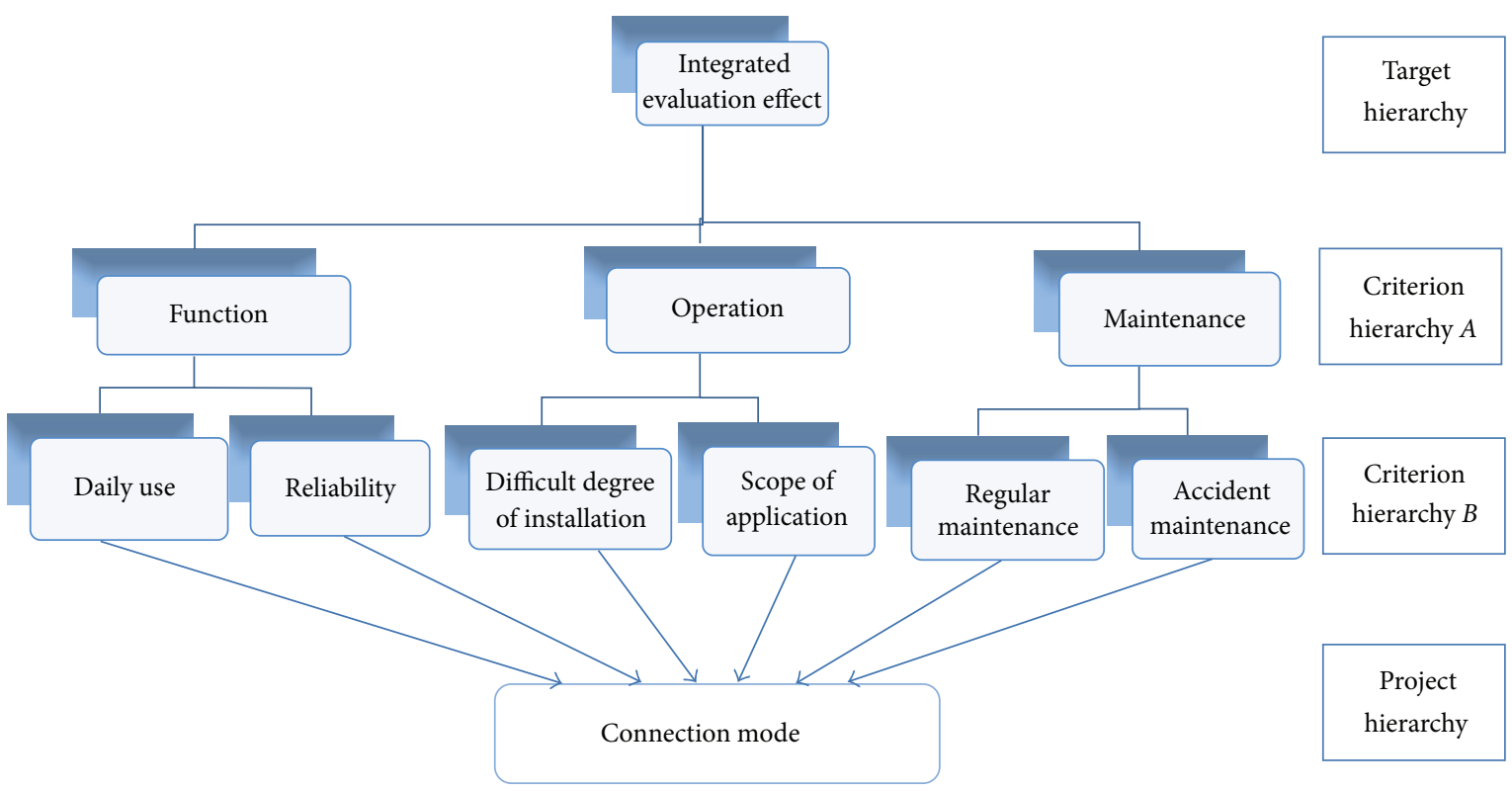

FIgURE 1: Analytic hierarchy system.

In 2003, the UK, France, Germany, and some other European countries jointly launched the "RISER" plan to collect and analyze the roadside safety data.

In China, there is little research about the roadside breakaway traffic signs currently. In 2005, Tang suggested that, to reduce the crash of uncontrolled vehicles and traffic signs, the traffic signs should be set in which there may exist some trouble for the vehicle to run out of the driveway; if not, the structure of disintegration of energy dissipation can be used on the signpost [13]. Sun et al. made a fullscaled introduction to the basic design, working principle, and design methods of the safety standards of American breakaway facilities [14]. Gao mainly studied the concept and methods of roadside safety design [15].

From the above, American scholars presently made a mass of the experiments in full-scaled collision validation of real vehicle about the research of roadside breakaway traffic signs and meanwhile put these signs into practice on highway. However, in comparison, China is just introduced into the "forgiving" design concept right now, and it still remains a state of prefeasibility studies for the related design concept and methods of breakaway traffic signs.

In general, the materials can be divided into two categories, plastic materials and brittle materials, whose classification is based on the size of elongation of tensile and compression test under the condition of normal temperature and static load. Putting the different mechanical property of plastic materials and brittle materials into the design of connection of the signpost and into the base, there are three types of connection: plastic, brittle, and rigid connection. Developing the research on the connection of roadside breakaway traffic signpost and base fit for China can provide some support and decision-making bases for the theory.

\section{Hierarchy Model}

Analytic Hierarchy Process (AHP) is a hierarchical weighted decision-making analysis theory brought up by T. L. Saaty in the 1970s. It is a decision-making analysis method with features of concision, flexibility, and systematization. Thus, AHP was chosen to make a comprehensive evaluation for the connection between pole and base of roadside breakaway sign.

2.1. Hierarchical Analysis System. The AHP divided the evaluated issues into three levels, that is, the target hierarchy, criterion hierarchy, and project hierarchy.

The integrated effect of the connection mode of breakaway traffic signs was considered as the target hierarchy in this evaluation.

The criterion hierarchy includes the factors to be considered and subfactors. This integrated evaluation consists of two layers. $A$ includes function, operation, and maintenance. $B$ consists of daily use, reliability, difficult degree of installation, scope of application, regular maintenance, and accident maintenance.

Project hierarchy contains plastic, brittle, and rigid connections of breakaway traffic signs.

The hierarchical structure of the integrated evaluation of breakaway traffic signs was shown in Figure 1.

2.2. Comparison Judgment Matrix. Constructing the judgment matrix needs endowing certain weight to the evaluation indexes between the two criterion hierarchies. The form of comparison judgment matrix was shown as

$$
A\left(a_{i j}\right)_{n \times n}=\left(\begin{array}{ccc}
a_{11} & \cdots & a_{1 n} \\
\vdots & \ddots & \vdots \\
a_{n 1} & \cdots & a_{n n}
\end{array}\right),
$$


TABLE 1: Dimension of judgment matrix.

\begin{tabular}{|c|c|}
\hline Comparison result & Implication \\
\hline 1 & $\begin{array}{l}\text { The factor } i \text { has the same effect as the } \\
\text { factor } j \text {. }\end{array}$ \\
\hline 3 & $\begin{array}{l}\text { The effect of factor } i \text { is slightly stronger } \\
\text { than that of factor } j \text {. }\end{array}$ \\
\hline 5 & $\begin{array}{l}\text { The effect of factor } i \text { is stronger than that } \\
\text { of factor } j \text {. }\end{array}$ \\
\hline 7 & $\begin{array}{l}\text { The effect of factor } i \text { is apparently } \\
\text { stronger than that of factor } j \text {. }\end{array}$ \\
\hline 9 & $\begin{array}{l}\text { The effect of factor } i \text { is absolutely stronger } \\
\text { than that of factor } j \text {. }\end{array}$ \\
\hline $2,4,6,8$ & $\begin{array}{l}\text { The corresponding scale value between } \\
\text { the two levels above. }\end{array}$ \\
\hline Reciprocal & $\begin{array}{l}\text { The importance scale of the latter to the } \\
\text { former in comparison. }\end{array}$ \\
\hline
\end{tabular}

where $a_{i j}$ represents the comparison result between factor $i$ and factor $j . a_{i j}$ is an integer and it ranges from 1 to 9 , which is shown in Table 1 .

There are double evaluation indexes in this integrated evaluation; thus it is necessary to construct four comparison judgment matrices, that is, the comparison judgment matrix of one criterion hierarchy $A$ and three criterion hierarchies $B$. They were shown as follows:

$$
\begin{aligned}
& A=\left(\begin{array}{lll}
1 & 2 & 5 \\
\frac{1}{2} & 1 & 3 \\
\frac{1}{5} & \frac{1}{3} & 1
\end{array}\right), \\
& B_{1}=\left(\begin{array}{ll}
1 & \frac{1}{3} \\
3 & 1
\end{array}\right), \\
& B_{2}=\left(\begin{array}{ll}
1 & 2 \\
\frac{1}{2} & 1
\end{array}\right), \\
& B_{3}=\left(\begin{array}{ll}
1 & \frac{1}{2} \\
2 & 1
\end{array}\right) .
\end{aligned}
$$

Firstly, judgment matrix $A$ needs to be normally processed. The normalization processing method employed herein is to divide each factor in the matrix by the sum of each column. Matrix $A$ after normalization processed can be gotten as follows:

$$
A=\left(\begin{array}{lll}
0.59 & 0.60 & 0.56 \\
0.29 & 0.30 & 0.33 \\
0.12 & 0.10 & 0.11
\end{array}\right)
$$

Then find the average value for the elements of each line, and get the corresponding normalized vector $W=$ $\left(w_{1}, w_{2}, w_{3}\right)$. The following is to sum up the elements of the obtained vector by $A \times W$ and get the maximum value $\lambda_{\max }$.
TABLE 2: The value of RI.

\begin{tabular}{cccccccccccc}
\hline$n$ & 1 & 2 & 3 & 4 & 5 & 6 & 7 & 8 & 9 & 10 & 11 \\
\hline RI & 0 & 0 & 0.58 & 0.90 & 1.12 & 1.24 & 1.32 & 1.41 & 1.45 & 1.49 & 1.51 \\
\hline
\end{tabular}

The weight vector can be gotten as $W_{A}=(0.58,0.31$, $0.11)^{T}$. By $A W=\lambda W$, it can be gotten that $W_{A}=(1.75,0.93$, 0.33 ), and maximum value $\lambda_{\max }=3.01$.

If the comparison judgment matrix does not become consistent, $\lambda_{\max }>n$, and $W$ cannot reflect the power in the target. CI was defined as measuring index of inconsistency degree:

$$
\mathrm{CI}=\frac{\lambda_{\max }-n}{n-1}
$$

Average random consistency index, RI, was introduced. The values of RI were shown in Table 2.

$\mathrm{CR}$ was defined as the consistency ratio:

$$
\mathrm{CR}=\frac{\mathrm{CI}}{\mathrm{RI}}
$$

If $\mathrm{CR} \leqslant 0.1$, then the comparison judgment matrix can pass the consistency test in which normalized feature vector can be used as the weight vector. If $\mathrm{CR}>0.1$, then the matrix cannot pass the consistency test and matrix needs reconstruction.

In this evaluation, CI was calculated:

$$
\mathrm{CI}=\frac{\lambda_{\max }-n}{n-1}=0.005,
$$

and when $n=3, \mathrm{RI}=0.58$, and $\mathrm{CR}=0.005 / 0.58=0.0086<$ 0.10 , comparison judgment matrix passed the consistency test.

In the same way, $W_{B_{1}}=(0.75,0.25)^{T}, W_{B_{2}}=(0.33,0.67)^{T}$, and $W_{B_{1}}=(0.34,0.66)^{T}$.

\section{Standardized Processing of Evaluation Index and Evaluation Results}

3.1. The Standardized Processing of Evaluation Indexes. In AHP, different indicators have different absolute figure and dimension, and the evaluation index is a weighted average of the different evaluation indexes in different weights. If directly weighted, a violation of the principles of mathematics will appear. Therefore, different indicators must be normalized before a comprehensive evaluation.

3.1.1. Function Indexes. The functions of roadside breakaway traffic signs include stability used daily and reliability. The roadside breakaway traffic sign needs to ensure the stability in daily use, while it will not cause major damage if the vehicle drives out of the lane.

In daily use, plastic connection is the most stable for breakaway traffic sign, and therefore the value of plastic connection is considered as best in this evaluation, and the value of standardization in daily use is 100 . As for the rigid 
TABLE 3: Specified value of function indexes.

\begin{tabular}{lccc}
\hline Connection type & Plastic & Brittle & Rigid \\
\hline Stability in daily use & 100 & 90 & 50 \\
Reliability in accident & 90 & 100 & 50 \\
\hline
\end{tabular}

TABLE 4: Specified value of operation indexes.

\begin{tabular}{lccc}
\hline Connection type & Plastic & Brittle & Rigid \\
\hline Installation difficulty & 100 & 80 & 40 \\
Scope of application & 70 & 100 & 50 \\
\hline
\end{tabular}

connection, the tightness of rigid bolt is hard to control. If bolt is set too loose, it cannot meet requirements for daily use. If bolt is set over-tightening, it is uncertain whether in a crash the bolt can be pulled out and two plates can be separated to prevent the vehicle and the occupant from being harmed. Thus there exists a lowest value of 50 .

In a collision, brittle connection can be easily broken and break away while being collided from all directions. Hence the accident reliable standardization for brittle connection was set as 100 in this evaluation. As for rigid connection, if the screws on the two steel plates are set tightly, there will be no guarantee of the disintegration when an accident occurs. It can do great harm to the vehicle and the occupants. Thus it is set as 50 for rigid connection. Specified value of function indexes was shown in Table 3.

3.1.2. Operation Indexes. Operation indexes include difficult degree of installation and scope of application. The installation of breakaway traffic signs with plastic connection is the same as general signs installation. Therefore plastic connection is regarded as the easiest installation, and the fixed value of the difficult degree of installation is 100 in this evaluation. The installation of brittle connection of breakaway traffic mark needs cork, steel, or aluminum bolt to connect the post with fixed coupling on the base. Meanwhile the breakaway traffic marks of the rigid connection require two parallel steel plates and the tightness of the bolt used to make sure that two steel plates were moderate. It is the most difficult installation, so this value is set as 40 for rigid connection.

Plastic connection can be used in single-pole traffic signs and be very applicable to each direction of collision. Nevertheless, plastic connection cannot be used in dual-pole traffic signs. In this evaluation, its application value was set as 70.

The fixed coupling of brittle connection can use cork, steel bolt, or brittle materials such as aluminum, and its scope of application is the most extensive. Thus its application value was set as 100 .

Rigid connection can be divided into one-way disintegration and multiway disintegration. Its forced direction is small in range. If the collision is not specified in the design direction, the goal would not be achieved in disintegration and energy dissipation as well as occupant protection. Hence, its application value was set as 50 .
TABLE 5: Specified value of maintenance indexes.

\begin{tabular}{lccc}
\hline Connection type & Plastic & Brittle & Rigid \\
\hline Conventional maintenance & 100 & 80 & 50 \\
Accident maintenance & 50 & 80 & 100 \\
\hline
\end{tabular}

Specified values of operation indexes were shown in Table 4.

3.1.3. Maintenance Indexes. Maintenance indicators include conventional maintenance and the accident maintenance.

Breakaway traffic signs with plastic connection do not require special routine maintenance. Therefore the value of conventional maintenance evaluation was set as 100. Breakaway traffic signs with rigid connection sometimes require checking two parallel plate coupling bolts, and the bolts must be tightened properly. Its conventional maintenance is the most complex. Thus its conventional maintenance evaluation value was set as 50 .

After the accident, breakaway traffic signs with plastic connection require complete replacement of masts. Its accident maintenance is the most difficult, and the recovery rate of the rod comes to the lowest. Therefore the value of its accident maintenance was set as 50 .

Breakaway traffic signs with rigid connection only need to replace the bolts, so the accident maintenance is the simplest one. Hence, the value of its accident maintenance was set as 100. Specified value of maintenance indexes was shown in Table 5 .

3.2. The Integrated Evaluation Results. From the abovementioned analysis, what has been acquired in criterion layer $B$ of comprehensive evaluation model is the weights and standardized scores of all the indicators. The following is the evaluation of three connection modes based on AHP.

At first, $A_{i j}$ was set as scoring matrix of all evaluation indexes in criterion layer $A$, and $B_{i j}$ was set as scoring matrix of all the evaluation indexes in criterion layer B. $i$ stood for evaluation index, while $j$ stood for types of connection mode. Then

$$
A_{i j}=B_{i j} \cdot W_{B}^{T}
$$

where $B_{i j}$ represents weight of each index in criterion layer $B$, shown in Tables 3, 4, and 5. Then

$$
A=\left(\begin{array}{lll}
92.5 & 97.5 & 50.0 \\
90.1 & 86.6 & 43.3 \\
66.5 & 80.0 & 83.5
\end{array}\right)
$$

The comprehensive evaluation scores were calculated as follows:

$$
F=W_{A} \quad A=\left(\begin{array}{lll}
88.9 & 92.9 & 51.6
\end{array}\right) .
$$

Evaluation results show that brittle connection mode for breakaway sign gets the highest score, 92.9, and rigid connection mode gets the lowest score, 51.6. Plastic connection mode, whose score is 88.0 , falls in between brittle and rigid connection mode. 
TABLE 6: Model material property.

\begin{tabular}{lccc}
\hline Material & $\begin{array}{c}\text { Young's } \\
\text { modulus }(\mathrm{Pa})\end{array}$ & $\begin{array}{c}\text { Poisson's } \\
\text { ratio }\end{array}$ & $\begin{array}{c}\text { Density } \\
\left(\mathrm{kg} / \mathrm{m}^{3}\right)\end{array}$ \\
\hline Q235 steel & $2.1 E 11$ & 0.33 & 7850 \\
F2-Maluminium alloy & $0.7 E 11$ & 0.33 & 2730 \\
\hline
\end{tabular}

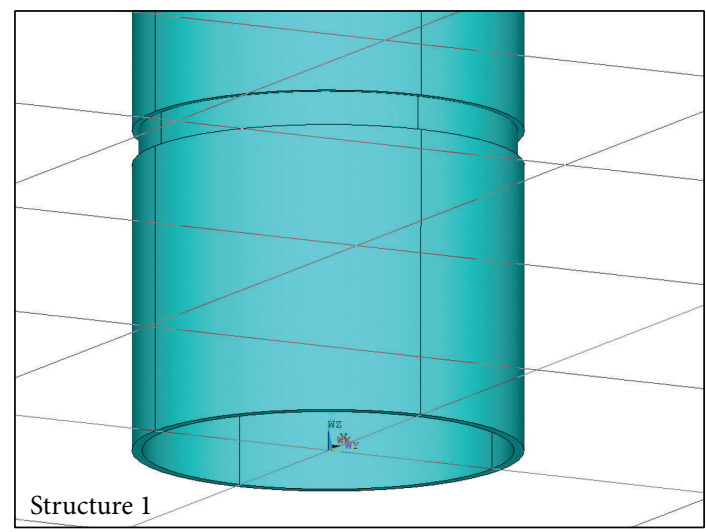

FIGURE 2: The model of recessed connection design structure.

\section{The Structure Design Based on Finite Element Simulation}

4.1. Model Building. Building a single-post traffic sign requires to choose the diameter of $800 \mathrm{~mm}$ and $3 \mathrm{~mm}$ thickness of LF2-m aluminum plate for sign board to select the steel tube with length of $2.8 \mathrm{M}$, diameter of $89 \mathrm{~mm}$, and thickness of $4.5 \mathrm{~mm}$ for the rod. The rod is made up of model Q235 steel. The given material properties were shown in Table 6. ANSYS software was adopted to establish models and analysis. Pretreatment module of ANSYS finite element software also provides a powerful tool for meshing. Free mesh was used, and cell shape was tetrahedron and classification accuracy was 5 .

\subsection{Structural Design}

4.2.1. Recessed Connection Design Structure. To obtain a significant changed coupling structure at the cross-sectional form, there is a need to set the groove in the coupling. The thickness of the post was $4.5 \mathrm{~mm}$, the thickness of the recess was $1.5 \mathrm{~mm}$, and the height was $8 \mathrm{~mm}$. The model of recessed connection design structure was shown in Figure 2.

Through the preprocessor of the ANSYS software, constraints and the most unfavorable loads were imposed on structure model. Then the solution was obtained, and color cloud of postprocessor was used to analyze the results, which were shown in Figures 3 and 4.

According to the stress analysis towards the divided unit of the recessed connection design structure, the results were shown in Table 7. As can be seen from Table 7, the maximum tensile stress of recessed connection structure was $7.30 \times 10^{8} \mathrm{~N}$, and it was more than the ultimate tensile strength of $455 \mathrm{MPa}$ of Q235 steel. Thus it indicates that

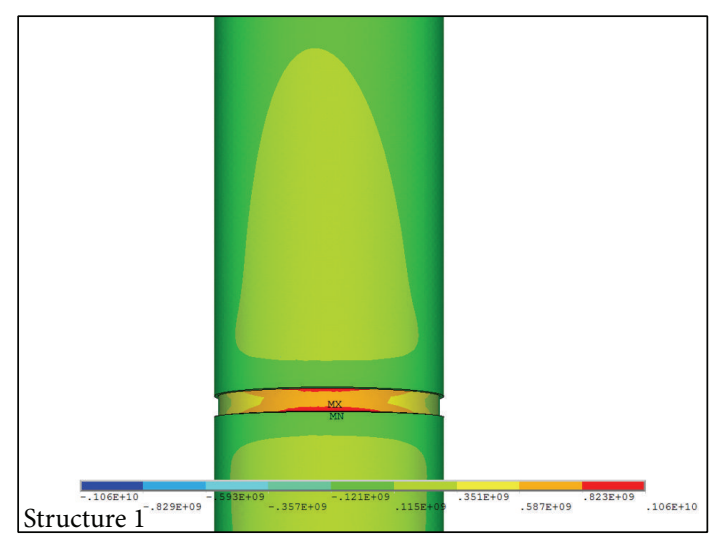

FIGURE 3: The collision directional stress of recessed connection design structure.

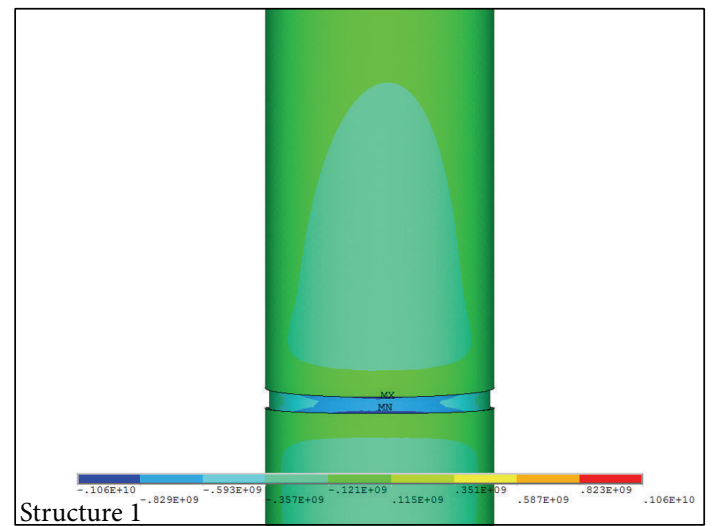

FIgure 4: The wind load directional stress of recessed connection design structure.

designed recessed connection structures in this paper can be breakaway in collision and play a role in protecting vehicle occupants.

4.2.2. Hole-Type Connection Design Structure. Similar to recessed connection design structure, the hole-type connection design structure sets some holes to make the connection parts a weak stress surface in the collision course and takes some effect in energy dissipation. The diameter of 4 set holes was $8 \mathrm{~mm}$ in the position of the connection structure, and the angle of each hole evenly spaced was $90^{\circ}$, which was shown in Figure 5.

Through the preprocessor of the ANSYS software, constraints and the most unfavorable loads were imposed on structure model. Then the solution was obtained, and color cloud of postprocessor was used to analyze the results, which were shown in Figures 6 and 7.

According to the stress analysis towards the divided unit of the hole-type connection design structure, the results were shown in Table 8 . It could be seen from Table 8 that the maximum tensile stress of hole-type connection structure was $5.17 \times 10^{8} \mathrm{~N}$, and it was more than the ultimate tensile strength of $455 \mathrm{MPa}$ of Q235 steel. Thus designed hole-type 
TABLE 7: The stress of recessed connection design structure.

\begin{tabular}{lccc}
\hline Number & Stress $(\mathrm{Pa})$ & Number & Stress $(\mathrm{Pa})$ \\
\hline 1 & $-1.35 E+06$ & 16 & $-4.50 E+06$ \\
2 & $1.52 E+08$ & 17 & $-4.44 E+07$ \\
3 & $3.02 E+08$ & 18 & $-8.19 E+07$ \\
4 & $4.36 E+08$ & 19 & $-1.16 E+08$ \\
5 & $5.48 E+08$ & 20 & $-1.44 E+08$ \\
6 & $6.38 E+08$ & 21 & $-1.66 E+08$ \\
7 & $6.96 E+08$ & 22 & $-1.81 E+08$ \\
8 & $7.30 E+08$ & 23 & $-1.89 E+08$ \\
9 & $7.17 E+08$ & 24 & $-1.89 E+08$ \\
10 & $6.74 E+08$ & 25 & $-1.81 E+08$ \\
11 & $6.21 E+08$ & 26 & $-1.66 E+08$ \\
12 & $5.37 E+08$ & 27 & $-1.44 E+08$ \\
13 & $4.19 E+08$ & 28 & $-1.15 E+08$ \\
14 & $2.89 E+08$ & 29 & $-8.19 E+07$ \\
15 & $1.47 E+08$ & 30 & $-4.44 E+07$ \\
\hline
\end{tabular}

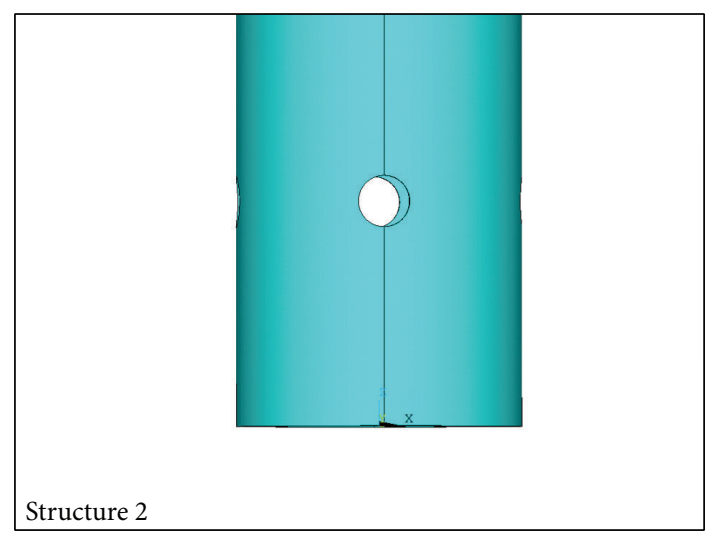

FIgURE 5: The model of hole-type connection design structure.

connection structures can also be breakaway in collision and protect vehicle occupants.

4.2.3. Contrastive Analysis between Proposed Models and Regular Sign. A contrastive analysis between proposed models and regular sign was conducted, which indicated the advantages of the proposed models.

According to the stress analysis towards the divided unit of regular sign structure, the results were shown in Table 9. It showed that the maximum tensile stress of regular sign structure was $1.96 \times 10^{8} \mathrm{~N}$, and it was less than the ultimate tensile strength of $455 \mathrm{MPa}$ of Q235 steel. Thus regular sign structure cannot be breakaway in collision and protect vehicle occupants.

\section{Conclusion}

In this paper, the researcher adopted the Analytic Hierarchy Process to evaluate the connection mode between roadside sign post and bases. AHP evaluation results show that the best connectivity option is brittle joining, and its overall

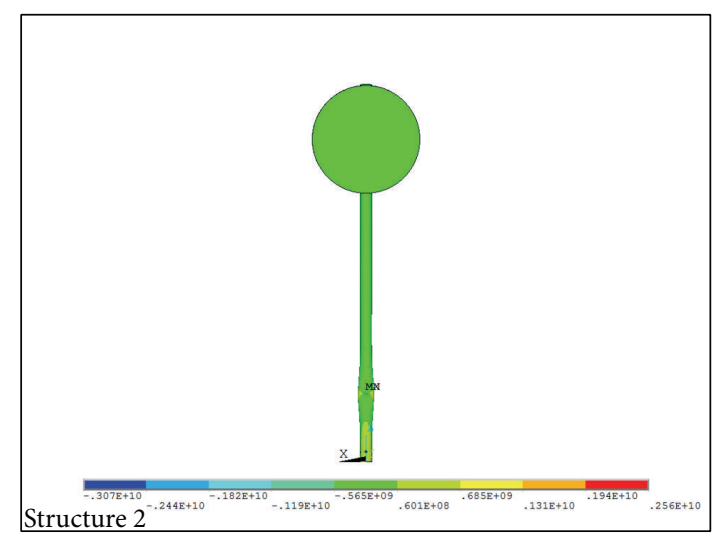

FIGURE 6: The collision directional stress of the hole-type connection design structure.

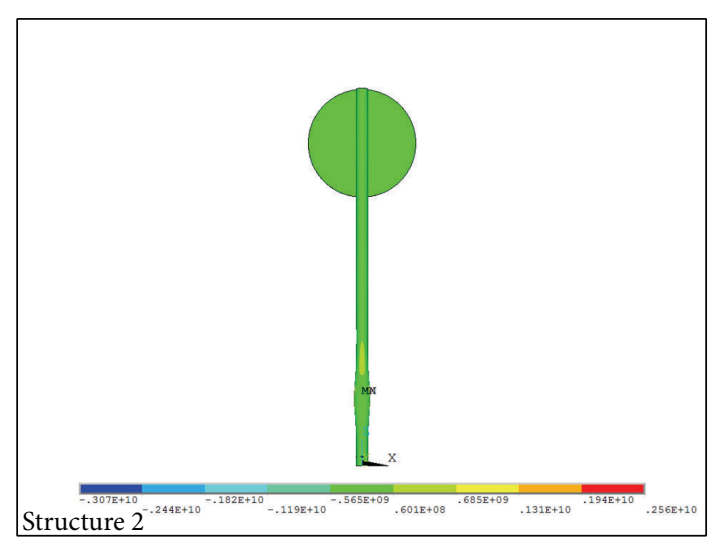

FIgure 7: The wind load directional stress of the hole-type connection design structure.

TABLE 8: The stress of the hole-type connection design structure.

\begin{tabular}{lccc}
\hline Number & Stress $(\mathrm{Pa})$ & Number & Stress $(\mathrm{Pa})$ \\
\hline 1 & $4.74 E+07$ & 13 & $-6.54 E+07$ \\
2 & $7.14 E+07$ & 14 & $-7.67 E+07$ \\
3 & $1.03 E+08$ & 15 & $-1.05 E+08$ \\
4 & $1.28 E+08$ & 16 & $-1.28 E+08$ \\
5 & $3.50 E+08$ & 17 & $-1.47 E+08$ \\
6 & $4.15 E+08$ & 18 & $-2.09 E+08$ \\
7 & $5.17 E+08$ & 19 & $-2.12 E+08$ \\
8 & $4.50 E+08$ & 20 & $-1.47 E+08$ \\
9 & $3.28 E+08$ & 21 & $-1.28 E+08$ \\
10 & $1.03 E+08$ & 22 & $-1.06 E+08$ \\
11 & $7.23 E+07$ & 23 & $-7.72 E+07$ \\
12 & $5.30 E+07$ & 24 & $-7.34 E+07$ \\
\hline
\end{tabular}

score is 92.9. Plastic joining is in between; its comprehensive evaluation score is 88.9. Rigid connection is the worst way, and its overall score is 51.6.

Selecting the ANSYS simulation software, recessed connection structure model and hole-type connection structure model were established. According to stress analysis by 
TABLE 9: The stress of regular sign structure.

\begin{tabular}{lccc}
\hline Number & Stress $(\mathrm{Pa})$ & Number & Stress $(\mathrm{Pa})$ \\
\hline 1 & $4.49 E+06$ & 16 & $-4.50 E+06$ \\
2 & $3.62 E+07$ & 17 & $-4.44 E+07$ \\
3 & $7.57 E+07$ & 18 & $-8.19 E+07$ \\
4 & $1.12 E+08$ & 19 & $-1.16 E+08$ \\
5 & $1.44 E+08$ & 20 & $-1.44 E+08$ \\
6 & $1.70 E+08$ & 21 & $-1.66 E+08$ \\
7 & $1.87 E+08$ & 22 & $-1.81 E+08$ \\
8 & $1.96 E+08$ & 23 & $-1.89 E+08$ \\
9 & $1.96 E+08$ & 24 & $-1.89 E+08$ \\
10 & $1.87 E+08$ & 25 & $-1.81 E+08$ \\
11 & $1.70 E+08$ & 26 & $-1.66 E+08$ \\
12 & $1.44 E+08$ & 27 & $-1.44 E+08$ \\
13 & $1.12 E+08$ & 28 & $-1.15 E+08$ \\
14 & $7.57 E+07$ & 29 & $-8.19 E+07$ \\
15 & $3.62 E+07$ & 30 & $-4.44 E+07$ \\
\hline
\end{tabular}

imposing the most unfavorable load combinations, their validity has been tested.

One shortcoming of this paper is the fact that specified values of evaluation indexes were determined according to qualitative analysis. Quantitative analysis is needed to make values of evaluation indexes more reasonable. The other deficiency of this paper is the lack of real examples; the test should be conducted for analyzing connection between signpost and base in the next research.

\section{Conflict of Interests}

The authors declare that there is no conflict of interests regarding the publication of this paper.

\section{Acknowledgment}

This research was sponsored by Jilin Province Science and Technology Development Project (20140413057GH and 20140204026SF).

\section{References}

[1] T. C. Edwards, T. J. Hirsch, and R. M. Olson, Break-Away Roadside Sign Support Structures, Texas Transportation Institute, College Station, Tex, USA, 1967.

[2] D. L. Ivey, R. M. Olson, C. E. Buth, T. J. Hirsch, and D. L. Hawkins, "Breakaway overhead sign bridges, crash testing," Highway Research Record, no. 34, pp. 35-46, 1971.

[3] J. E. Martinez, R. M. Olson, and E. R. Post, "Impact response of overhead sign bridges mounted on breakaway supports," Highway Research Record, no. 34, pp. 23-34, 1971.

[4] C. E. Kimball and J. D. Michie, "Pendulum tests of breakaway wood sign supports using crushable bumpers," Transportation Research Record, no. 679, pp. 33-38, 1978.

[5] W. M. Szalaj and R. L. Hollinger, "New Jersey breakaway sign testing," Transportation Research Record, no. 1004, pp. 67-73, 1985.
[6] "Looking at breakaway supports for signs," Better Roads, vol. 58, no. 8, pp. 26-27, 1988.

[7] T. D. Davis, "Signs on breakaway barricades. Wind and crash tests," Transportation Research Record, no. 1258, pp. 1-12, 1990.

[8] J. D. Reid, "Dual-support breakaway sign with modified fuse plate and multidirectional slip base," Transportation Research Record, no. 1528, pp. 61-68, 1996.

[9] G. W. Paulsen and J. D. Reid, "Nonlinear finite-element analysis of dual support breakaway sign," Transportation Research Record, no. 1528, pp. 146-154, 1996.

[10] J.-P. Pinelli, C. S. Subramanian, and J. Tabora, "Experimental study of breakaway highway sign connections," Journal of Transportation Engineering, vol. 128, no. 1, pp. 17-20, 2002.

[11] U.S. Department of Transportation. Federal Highway Administration, "Maintenance of signs and sign supports," Tech. Rep. FHWA-SA-09-025, FHWA, Washington, DC, USA, 2010.

[12] AASHTO, Roadside Design Guide, AASHTO, Washington, DC, USA, 2011.

[13] C. C. Tang, "Roadside safety consideration and countermeasures of signs set," Journal of Highway and Transportation Research and Development, vol. 22, no. 9, pp. 142-145, 2005.

[14] R. Sun, Y. L. He, X. D. Sun et al., "The American roadside disintegration of energy dissipation facilities design," Road Traffic and Safety, vol. 4, no. 6, pp. 34-37, 2006.

[15] H. L. Gao, Roadside Safety Design and Guidance, China Communication Press, 2008. 


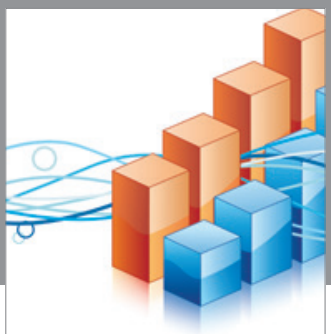

Advances in

Operations Research

vatem alat4

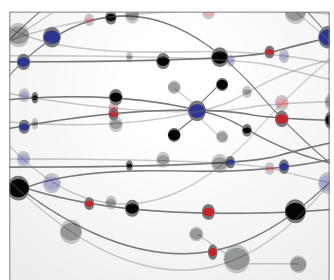

\section{The Scientific} World Journal
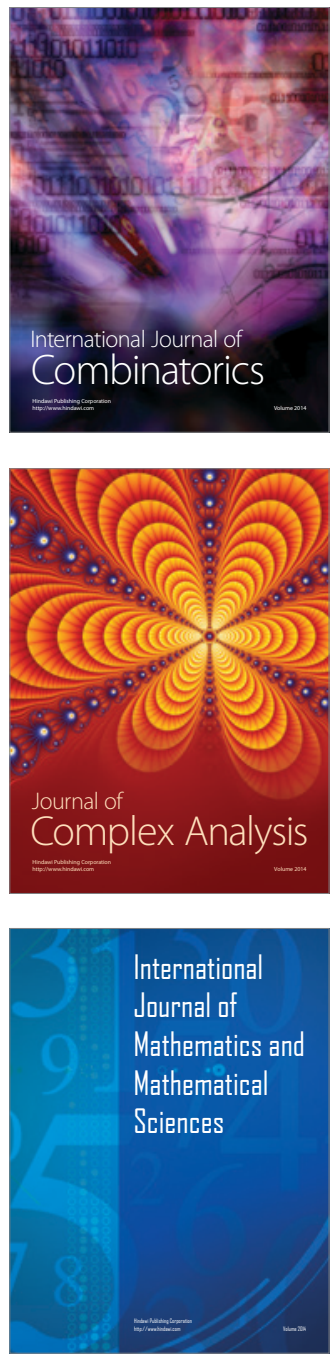
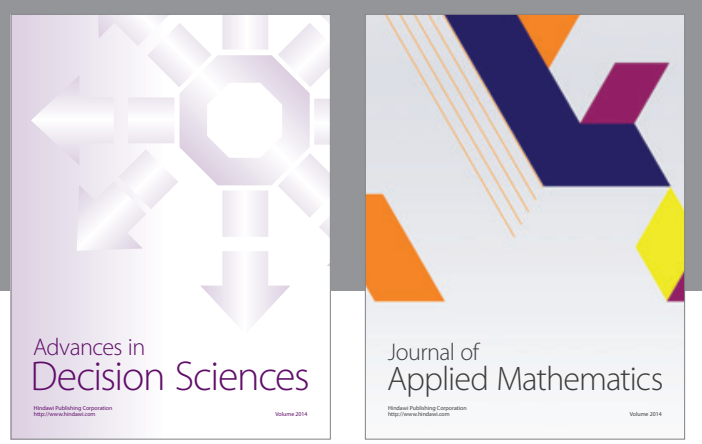

Algebra

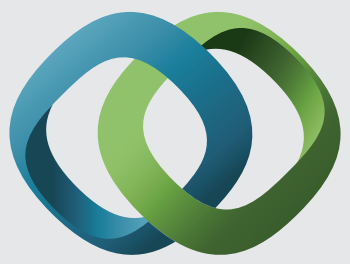

\section{Hindawi}

Submit your manuscripts at

http://www.hindawi.com
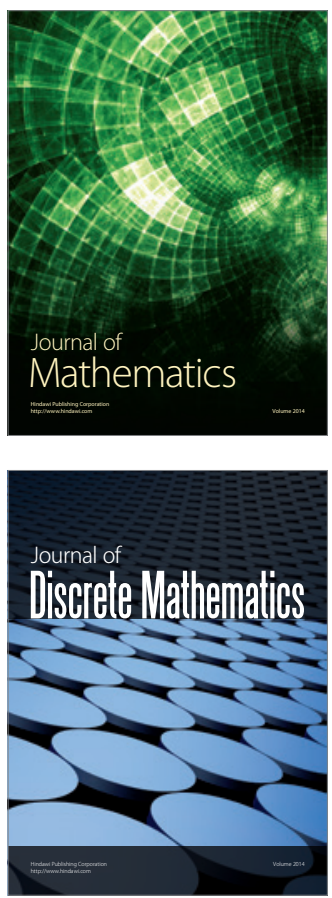

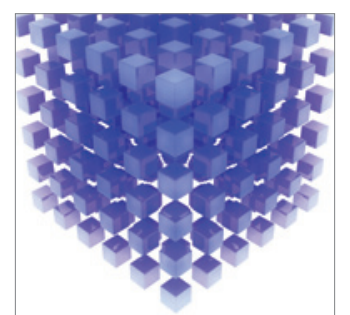

Mathematical Problems in Engineering
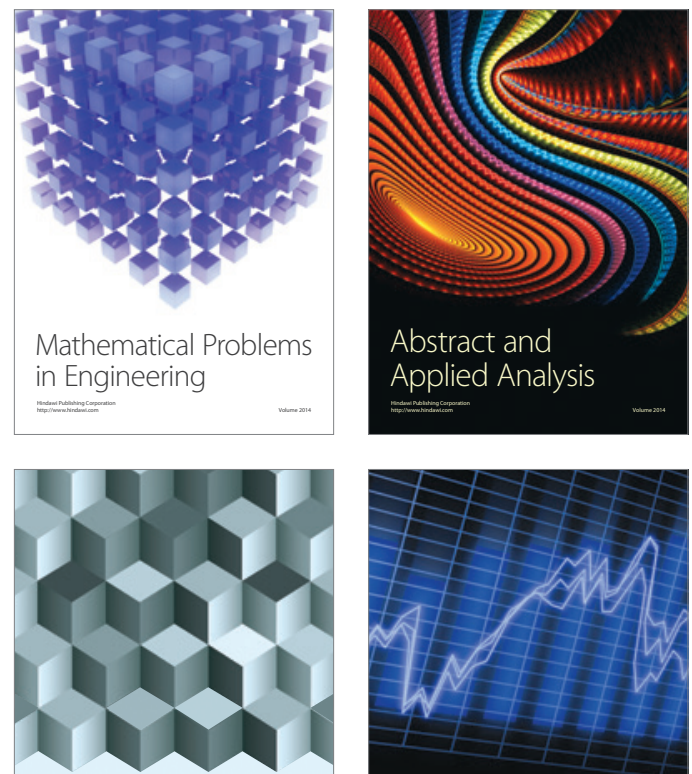

Journal of

Function Spaces

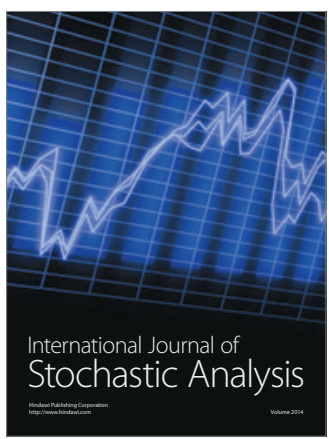

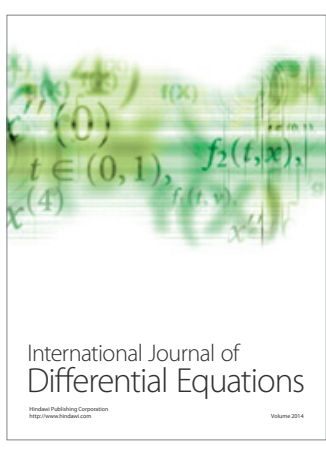
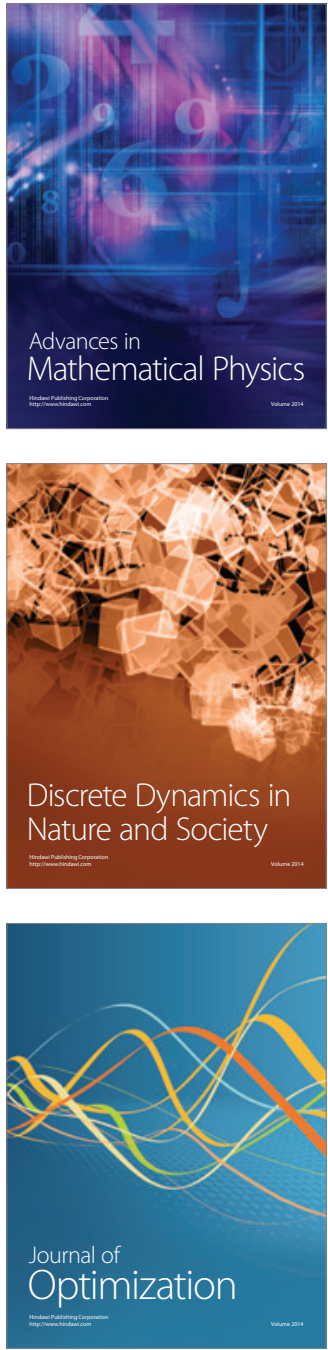